\section{artelogie}

\section{Artelogie}

Recherche sur les arts, le patrimoine et la littérature de l'Amérique latine

16 | 2021

Fotografía y migraciones, siglos XIX-XXI.

Estéticas En Colombia Siglo XXI.V Tomo de la Colección Pensamiento Estético Siglos XX y XXI, Ediciones Desde abajo, 2020, 334 págs.

\title{
Carlos Fajardo Fajardo
}

\section{(2) OpenEdition}

Journals

\section{Edición electrónica}

URL: https://journals.openedition.org/artelogie/9337

DOI: $10.4000 /$ artelogie.9337

ISSN: 2115-6395

\section{Editor}

Association ESCAL

\section{Referencia electrónica}

Carlos Fajardo Fajardo, «Estéticas En Colombia Siglo XXI.V Tomo de la Colección Pensamiento Estético Siglos XX y XXI, Ediciones Desde abajo, 2020, 334 págs.», Artelogie [En línea], 16 | 2021, Publicado el 27 enero 2021, consultado el 02 septiembre 2021. URL: http://journals.openedition.org/artelogie/9337 ; DOI: https://doi.org/10.4000/artelogie.9337

Este documento fue generado automáticamente el 2 septiembre 2021.

Association ESCAL 


\title{
Estéticas En Colombia Siglo XXI.V Tomo de la Colección Pensamiento Estético Siglos XX y XXI, Ediciones Desde abajo, 2020, 334 págs.
}

\author{
Carlos Fajardo Fajardo
}

1 La Colección Pensamiento Estético Siglos XX y XXI, publicada por Ediciones Desde abajo, Bogotá, Colombia, reúne una serie de textos escritos por los más representativos pensadores y creadores del Siglo XX. Su propósito es la divulgación de las múltiples reflexiones que, sobre el hecho artístico, se han producido en los dos últimos siglos. Cada título cuenta con un estudio introductorio, escrito por un experto en el respectivo tema. Tanto la calidad de los autores, como la amplitud de las temáticas, dan a la colección una gran fortaleza y riqueza teórica, lo que posibilita acercar al gran público a las fuentes y conceptos fundamentales sobre las prácticas artísticas desde las primeras vanguardias del pasado siglo, hasta los procesos de formación de nuevas categorías estéticas y de sensibilidades manifiestas en el presente.

2 Esta Colección surgió de la necesidad de ofrecer a la comunidad académica y al público en general una serie de libros que reunieran ensayos de los más connotados pensadores y creadores del siglo XX en los campos de la estética y del arte.

3 Esta apuesta y propuesta es un esfuerzo editorial importante en un país como Colombia donde son escasas - se diría casi nulas- las publicaciones de colecciones cuyo tema gire exclusivamente en torno a los problemas de la estética. De allí que la colección sea un aporte sustancial para la formación de públicos lectores del arte, como también una ayuda en el fortalecimiento de la sensibilidad con espíritu crítico de todo aquel que esté interesado en las propuestas estéticas de los siglos XX y XXI. Estos son sus mayores objetivos, sus más altos propósitos. La colección a publicado los sigientes títulos: Vanguardias artísticas del siglo XX; Estéticas del siglo XX; Poéticas del siglo XX; Estéticas en Colombia siglo XXI y Estéticas en Colombia siglo XXI. 
4 Este quinto tomo de la colección, titulado Estéticas en Colombia siglo XXI, congrega ensayos que realizan una cartografía de los procesos políticos, poéticos, novelísticos, teatrales, cinematográficos, ensayísticos y pictóricos actuales de un país bajo el dominio de una globalización mediática y de mercados, con notables hibridaciones de mentalidades, sensibilidades e imaginarios y una funesta tradición de violencia. De este modo, contiene textos que abordan los procesos políticos, históricos de una Colombia que fluctúa entre una premodernidad señorial, confesional, parroquial, hacendaria; un muy escaso espíritu moderno, asumido a cuenta gotas, y una impuesta globalización de mercados y de imaginarios mediáticos Estos procesos se sintetizan y manifiestan en nuestra no grata tradición de violencia mental, sensible e histórica. En esta dirección, los textos de los filósofos Rubén Jaramillo Vélez y Damián Pachón Soto dan cuenta de ello. Del mismo modo, el poeta e historiador Gustavo Adolfo Quesada Vanegas realiza un exhaustivo, riguroso y sintético recorrido por la historia de Colombia, mostrando las raíces y los orígenes de nuestra heterogeneidad multi-temporal política y cultural, como también las hibridaciones de imaginarios, sensibilidades y mentalidades, tratando de explicar nuestro estado actual de cultura bajo el dominio de un neoliberalismo financiero transnacional.

5 Para Fernando Cruz Kronfly el intelectual y el escritor colombiano viven en una Babel contemporánea, desde la cual deben pensar el olvido de un ser sumergido en lo sublime, el poder, la tiranía, los dogmas, la sangre, la crueldad, la violencia y el crimen. En esta Babel, el intelectual creador colombiano, está plantado "desde hace décadas sobre la sangre ya seca de las víctimas de arriba abajo, humedecida siempre por baldados de más sangre fresca en escalada siguen su camino". Su fuerza de creación no se detendrá ni será aniquilada por la violencia a la cual ha sido sometido. Por tanto, "es falso suponer que el clima ideal para el intelectual y el artista es el de la paz perpetua y el orden sin fisuras"

6 Asimismo, el pensar la poesía como hecho de conocimiento y su relación con el conflicto Colombiano es el aporte del poeta Jorge Eliécer Ordóñez Muñoz, cada vez que, la poesía, y sus creadores, son barómetros y termómetros espirituales de las presiones y temperaturas de su tiempo. Jorge Eliécer Ordóñez rastrea en la poesía colombiana las relaciones traumáticas de dichas poéticas con los contextos de una Colombia de mediados del siglo XX y principios del XXI. Ordóñez recupera de la fuente mitológica la figura paradójica de Filoctetes, de Sófocles, para reflexionar sobre Colombia. En sus palabras: "ese guerrero de arco y flecha infalibles, sin cuyo trabajo Troya no podía ser conquistada, soportaba una llaga fétida que lo condenaba a vivir aislado de sus compañeros...". Esa llaga supurante, fétida, ha sido y es la violencia en Colombia, fuente y matriz para la poesía de varias generaciones.

De igual manera, el poeta Juan Manuel Roca señala cómo la violencia ha tocado las puertas de la poesía colombiana, hasta poner la palabra en crisis y en peligro la lucidez del poeta. Para Roca, ejercer la lucidez "en medio de un país cruento donde la guerra siempre viene después de la postguerra, no resulta propicio cuando ese mismo país parece fijo como una bicicleta estática a un paisaje de barbarie acrecentado por diferentes fases de la violencia: la partidista, la guerrillera, la de la delincuencia común, la del terrorismo de estado y sus eslabones paramilitares, la del narcotráfico...La masacre de hoy borra la masacre de ayer pero anuncia la de mañana". De manera que, en la poesía colombiana se ven registradas y reflejadas todas estas heridas históricas, esos terribles "campos minados de nuestra violenta realidad". 
7 La novela colombiana actual, envuelta en una atmósfera de mercaderes, competitivos y mediáticos, es radiografiada por el escritor Pablo Montoya, invitando a ver con mayor claridad cómo se ha construido un canon literario a través de la violencia colombiana y de macro grupos editoriales y mediáticos donde la literatura ha adquirido un esquema de guión periodístico, "sensacionalista, poco audaz", junto a premios literarios "prestigioso", organizados y manipulados por agentes literarios, medios y escritores comerciales, que se amoldan a las pr5eferencias de los clientes.

8 Santiago Mutis Durán nos aproxima a reflexionar sobre cómo en las universidades se ha desterrado el ensayo creativo y literario, debido a la proliferación de los llamados "artículos académicos", destinados a las revistas indexadas institucionales. Éstas asumen el ensayo como un "producto", un "artefacto", desmontando su fuerza, su pasión, su íntima relación con la poesía y la vida. De allí que Santiago proponga un ejercicio ensayístico de análisis a la obra de Oscar Muñoz, con una personalísima y sensible mirada sobre la misma, y con una propuesta sugerente de escritura, levantada desde la poesía, con la cual habita, dialoga, con el trabajo de Muñoz.

9 La importancia de figuras como Carlos Mayolo, Luis Ospina y Andrés Caicedo en la formación de una tradición cinematográfica en Colombia, y especialmente en Cali, es observada de forma exhaustiva por el poeta y realizador audiovisual Julio César Goyes Narváez. Éste concentra su análisis en la influencia de las condiciones familiares y personales de estos tres creadores en sus películas, guiones y textos narrativos. A la vez, analiza la tradición del llamado Caliwood en los filmes producidos a finales del siglo XX y en el siglo XXI por directores de cine en Cali, sobre todo por el director Oscar Campo.

10 De igual forma, el pintor y escultor Fernando Maldonado pone en tela de juicio la educación recibida en las Escuelas y Academias de Bellas Artes en Colombia de finales del siglo XX, su deficiencia en los pensum, la mediocridad de los profesores y de la institución misma, influenciados por un posmodernismo yuxtapuesto, y una mentalidad colombiana dependiente, que generó y genera facilismo y banalidad creativa. La punzante aguja en la llaga que introduce Maldonado sobre su formación de artista, es una radiografía de nuestro estado actual educativo, no solo en lo referente al arte, sino en todos los niveles de la escolaridad en Colombia.

11 Reivindicar el trabajo del teatro de títeres como acción libertaria, imaginativa y poética, es para Iván Darío Álvarez E., director de la Libélula Dorada, el más grande propósito llevado a contra viento con pasión creativa, en un país que excluye, e ignora, el aporte del teatro de títeres a la imaginación, al espíritu crítico y a la cultura.

12 El actor y director de teatro César Badillo Pérez, nos propone pensar en los conceptos de presentación y re-presentación escénica, en los procesos de creación y de puesta en escena en el Teatro Colombiano, y sus vasos comunicantes con lo ético, lo estético, lo político, bajo un sistema neoliberal primordialmente mercantil.

13 En todos estos ensayos las condiciones del drama colombiano están expresadas. Es nuestro deseo que sus apuestas y propuestas sirvan para pensarnos como país, que ayuden a reflexionar y a conocer los procesos locales, nacionales, mundiales y las condiciones adversas que en la actualidad tanto nos afligen. 


\section{AUTOR}

\section{CARLOS FAJARDO FAJARDO}

Director y compilador de la

Colección Pensamiento Estético Siglos XX y XXI

es 